\title{
Carcinogênese hormonal e neoplasias hormônio-dependentes
}

\author{
Hormonal carcinogenesis and hormone dependents neoplasm
}

\author{
Alessandra Estrêla da Silva ${ }^{1}$ Rogéria Serakides $^{2}$ Geovanni Dantas Cassali ${ }^{3}$
}

\section{- REVISÃo BIBLIOGRÁFICA -}

\section{RESUMO}

\begin{abstract}
As neoplasias hormônio-dependentes podem originar-se de mutações genéticas resultantes da proliferação de células normais ou da multiplicação de células já transformadas por outros carcinógenos. Alguns hormônios e drogas anti-hormonais estão sendo utilizados com sucesso no tratamento dessas neoplasias em humanos. Apesar da freqüencia elevada das neoplasias hormônio-dependentes nos animais, seu tratamento com hormônios antagonistas $e$ fármacos anti-hormonais, bem como a identificação imunoistoquímica de receptores hormonais nas neoplasias não fazem parte da rotina dos hospitais veterinários.
\end{abstract}

Palavras-chave: carcinogênese, hormônios, tratamento, imunoistoquímica.

\section{ABSTRACT}

The hormone-dependent neoplasms may originate from genetic mutations resulting the normal cells proliferation or of the cells multiplication already transformed by other carcinogen. Some hormones and anti-hormones drugs are being used with success in the treatment of those neoplasm in humans. In spite of the elevated frequency of the hormone dependent neoplasms in the animals, the use of antagonistic hormones and anti-hormones drugs, as well as the identification immunohistochemical of hormones receptors in the neoplasm is not already part of the veterinary hospitals routine.

Key words: carcinogenesis, hormones, treatment, immunohistochemical.

\section{INTRODUÇÃO}

A atividade normal da célula depende da perfeita integração entre as várias vias metabólicas. Grande parte desse metabolismo é controlado pelos hormônios, lançados no sangue até os órgãos alvo.
Como as necessidades de um determinado hormônio variam continuamente, torna-se necessário que suas concentrações estejam sujeitas à regulação (GUYTON, 1991). Quando há descontrole da secreção hormonal, ocorre perda da homeostasia celular advindo várias alterações, dentre elas o câncer. Os hormônios estão dentre os vários fatores indutores ou promotores da carcinogênese. Sejam endógenos ou exógenos, eles estimulam a proliferação celular predispondo às alterações genéticas (HENDERSON \& FEIGELSON, 2000).

Os genes controlam a hereditariedade e as atividades celulares dia-a-dia. O câncer é causado, na maioria dos casos, por mutação ou ativação anormal dos genes que controlam o crescimento celular (LOURO, 2000), resultando em modificações progressivas da biologia celular caracterizadas por alterações na proliferação, diferenciação e na interação das células com o meio extracelular (COTRAN et al., 2000).

A cada ano, cresce o número de pessoas e de animais domésticos acometidos por algum tipo de neoplasia. $\mathrm{O}$ estilo de vida da sociedade moderna contribui para aumentar a exposição da população a alguns fatores ambientais, nutricionais, químicos e hormonais potencialmente carcinogênicos. É claro que a interferência do homem nos hábitos alimentares dos animais e no seu ambiente também o coloca sob o mesmo risco. Talvez essa seja uma das explicações pela qual a freqüência de algumas neoplasias se equiivale no homem e nos animais (MOULTON, 1990).

$\mathrm{Na}$ oncologia, é necessário ir além do diagnóstico e buscar informações sobre o prognóstico e a terapêutica mais eficiente para a neoplasia em

\footnotetext{
${ }^{\mathrm{I}}$ Médico Veterinário, Mestrando em Medicina Veterinária, Escola de Veterinária, Universidade Federal de Minas Gerais (UFMG). ${ }^{2}$ Médico Veterinário, Doutor, Professor Adjunto, Setor de Patologia, Departamento de Clínica e Cirurgia Veterinárias,UFMG, CP 567, Belo Horizonte, MG, Brasil. E-mail: serakide@dedalus.lcc.ufmg.br. Autor para correspondência.

${ }^{3}$ Médico Veterinário, Doutor, professor Adjunto, Instituto de Ciências Biológicas, UFMF, Laboratório de Patologia Comparada.
} 
questão. No câncer de mama humano, a imunomarcação de receptores para estrógeno e progesterona auxilia na escolha do tratamento. Mas, as chances de sucesso também estão relacionadas com o diagnóstico precoce já que as neoplasias decorrentes dos desequilíbrios hormonais, na sua fase inicial, ainda são hormônio-dependentes com melhor prognóstico em comparação àquelas que já adquiriram independência hormonal (NORMAN \& LITWACK, 1997).

O objetivo desta revisão é apresentar e discutir a ação dos hormônios na carcinogênese e o uso de hormônios e fármacos anti-hormonais no tratamento das neoplasias hormônio-dependentes.

\section{Carcinogênese}

A carcinogênese caracteriza-se por mutações genéticas herdadas ou adquiridas pela ação de agentes ambientais, químicos, hormonais, radioativos e virais, denominados carcinógenos (COTRAN et al., 2000). A carcinogênese compreende quatros estádios: a iniciação que se caracteriza pela exposição das células aos carcinógenos com conseqüente mutação e formação de clones celulares atípicos e a promoção, que se caracteriza pela multiplicação desses clones celulares. Nessa fase, a supressão do contato com os carcinógenos pode interromper o processo (PERATONI, 1998). A progressão e a conversão maligna das células compõem respectivamente o terceiro e o quarto estádios da carcinogênese. Neles, as células transformadas apresentam autonomia para proliferar e, pela perda da coesão e obtenção da mobilidade, tornam-se invasivas (COOPER, 1995; MAREEL \& LEROY, 2003).

Os principais alvos da alteração genética são os proto-oncogenes, os genes supressores tumorais e os genes que controlam a morte celular programada ou apoptose (DELFINO et al., 1997). Acredita-se que os genes reparadores do DNA também possuam papel de destaque na carcinogênese, pois qualquer anormalidade nesses genes predisporia a mutações no genoma com subseqüente transformação neoplásica (LOURO, 2000; COTRAN et al., 2000).

Os proto-oncogenes são genes promotores do crescimento e da diferenciação celular que controlam a divisão mitótica ordenada das células (McKINNELL, 1998). Eles são transformados em oncogenes pelo descontrole da expressão dos genes ou pela mutação, translocação ou rearranjo dos genes, resultando na síntese de um produto anormal, as oncoproteínas (CARREÑO et al., 1999).

O crescimento celular resulta da ação de vários fatores estimuladores ou inibidores da divisão celular produzidos no meio intra ou extracelular (MAREEL \& LEROY, 2003). O controle do crescimento celular é complexo e depende da expressão de vários genes, principalmente daqueles que codificam os fatores de crescimento e seus receptores (McKINNELL, 1998; CARREÑO et al., 1999).

Os oncogenes e seus produtos podem aumentar a expressão dos genes das ciclinas e das quinases ciclina-dependentes (CDK), responsáveis pela progressão ordenada das células nas diversas fases do ciclo celular (PINES, 1995; McKINNELL, 1998). No ciclo normal, quando a célula recebe sinais promotores para seu crescimento, a síntese de ciclinas $D$ e E é estimulada na fase $G_{1}$. A progressão das células da fase $S$ para a fase $G_{2}$ é facilitada pelo controle da ciclina A ligada a CDK2 e CDK1. O papel exato da ciclina A não é conhecido, mas evidências sugerem que ela seja indispensável para a replicação do DNA (PINES, 1995). No início da fase $G$ predomina a ciclina $\mathrm{B}$ que, ao formar complexos com CDK1, auxilia a passagem da célula para a fase $\mathrm{M}$ e fosforila proteínas necessárias para a mitose. As mutações que descontrolam a atividade das ciclinas e das CDK favorecem a proliferação celular (COTRAN et al., 2000).

Dentre os genes supressores tumorais, estão aqueles que regulam a transcrição nuclear e o ciclo celular (Rb, p53, BRCA-1, BRCA-2), os genes que regulam a transdução de sinais (NF-1, APC) e os receptores da superfície celular (receptor do TGF-b e caderinas) (DENG \& BRODIE, 2001). A pRb, produto do gene $\mathrm{Rb}$, é uma fosfoproteína nuclear expressa em todos os tipos celulares, que em sua forma ativa, inibe a progressão das células da fase $G_{1}$ para a fase $S$ do ciclo celular (LOURO, 2000).

O gene p53, denominado guardião do genoma, produz uma proteína que controla a replicação do DNA, a proliferação celular e a apoptose. Nas células com DNA alterado, a proteína p53 acumula-se no núcleo e liga-se ao DNA evitando sua replicação. Essa parada no crescimento celular na fase $\mathrm{G}_{1}$ permite à célula restaurar seu genoma (COTRAN et al., 2000). Entretanto, danos irreversíveis requerem a eliminação das células acometidas (PINES, 1995).

Os genes BRCA-1 e BRCA-2 são supressores tumorais. A função desses genes não é totalmente conhecida, mas acredita-se que estejam envolvidos no controle da transcrição (COTRAN et al., 2000). Mutações nesses genes predispõem ao desenvolvimento do câncer de mama, ovário, próstata, cólon, pâncreas e de laringe (DENG \& BRODIE, 2001; INGVARSSON, 2001).

Os produtos dos genes NF-1 e do gene APC também são supressores tumorais (COTRAN et al., 
2000). A proteína APC localiza-se no citoplasma e degrada a $\beta$-catenina, proteína que pode penetrar no núcleo e ativar a transcrição dos genes promotores do crescimento. Assim, mutações no gene APC estimulam a proliferação celular (COOPER, 1995). A neurofibromina, produto do gene NF-1 regula a transdução de sinais pela proteína ras e ativa a GTPase, enzima que facilita a conversão da proteína ras ativa em ras inativa. Com a mutação ou perda do gene NF-1, a proteína ras é mantida no seu estado ativo, estimulando também a proliferação celular (PERATONI, 1998).

Vários tipos de moléculas expressas na superfície celular podem controlar o crescimento e o comportamento da célula, tais como os receptores do TGF- $\beta$ que regulam a transcrição dos genes inibidores do crescimento e as proteínas que regulam a adesão celular representadas pelas caderinas (LOURO, 2000). Existe correlação positiva entre a agressividade do câncer, evidenciada pela menor sobrevida do paciente, e mutações nos gene CDH1 que codifica as caderinas (MAREEL \& LEROY, 2003).

Os genes que impedem ( $\mathrm{Bcl} 2, \mathrm{Bcl}-\mathrm{XL})$ ou induzem (Bax, Bad) à morte celular programada também são importantes na carcinogênese. $O$ primeiro gene inibidor da apoptose descrito foi o bcl-2 (LOURO, 2000). A inibição da apoptose pelo bcl-2 pode ocorrer em qualquer estádio do ciclo celular, porém os mecanismos envolvidos ainda não foram totalmente elucidados. Postula-se que o bcl-2 aumente o tempo de sobrevida das células, favorecendo a atuação de outros oncogenes sobre elas (DELFINO et al., 1997).

\section{Carcinogênese hormonal}

A hipótese de que alguns hormônios aumentam a incidência das neoplasias foi postulada pela primeira vez por BITTNER et al. (1948). Mas, ainda há controvérsias sobre a gênese das neoplasias hormônio-dependentes. Postula-se que na carcinogênese hormonal, diferente daquela induzida por vírus ou agentes químicos, a proliferação celular não necessita de um agente iniciador específico. Os hormônios induzem proliferação celular com conseqüentes mutações genéticas que darão origem à célula neoplásica (MEUTEN, 2002). No entanto, para CARREÑO et al. (1999), a participação dos hormônios na carcinogênese se restringe à proliferação das células já transformadas por outros carcinógenos. Os genes específicos envolvidos na progressão das neoplasias hormônio-dependentes permanecem desconhecidos, contudo, acredita-se que os oncogenes, os genes supressores tumorais e os genes do reparo do DNA estejam envolvidos na carcinogênese hormonal, principalmente naquela induzida pelos esteróides sexuais (HENDERSON \& FEIGELSON, 2000).

\section{Neoplasias hormônio-dependentes}

Dentre as neoplasias hormôniodependentes destacam-se as neoplasias da mama, útero (endométrio e musculatura lisa), ovário, testículo, próstata, tireóide e o osteossarcoma. Essas neoplasias compartilham do mesmo mecanismo de carcinogênese, mas sob a ação de hormônios específicos (HENDERSON et al., 1993; HENDERSON \& FEIGELSON, 2000).

A neoplasia mais freqüente nas fêmeas é o câncer de mama principalmente em mulheres (INGVARSSON, 2001) e cadelas (MEUTEN, 2002). As neoplasias de mama ocorrem quase que exclusivamente nas fêmeas, mas cães machos com hiperestrogenismo decorrente do sertolioma também podem apresentá-la (MEUTEN, 2002). O estrógeno, a prolactina (DENG \& BRODIE, 2001), a progesterona (VORHERR, 1987), os andrógenos (KODAMA \& KODAMA, 1970) e até os hormônios tireoidianos estão envolvidos na carcinogênese mamária (NOGUEIRA \& BRENTANI, 1996).

Os tumores da glândula mamária de cães tem interesse especial para os pesquisadores que trabalham com neoplasias por causa de algumas similaridades com o câncer de mama humano. Inclusive tem sido proposto, em muitos trabalhos, o estudo dessas lesões na espécies canina como modelo comparativo para espécie humana (SCHNEIDER, 1970; STRANDBERG \& GOODMAN, 1974; PELETEIRO, 1994).

Os tumores mamários espontâneos dos caninos apresentam várias características epidemiológicas, clínicas, biológicas e aparentemente genéticas, semelhantes ao da espécie humana. Entre estas, podem ser citadas: a faixa etária de aparecimento (SCHNEIDER, 1970; MOULTON, 1990), a morfologia (MOULTON, 1990), o efeito protetor da ovariectomia (MILLER, 1991), a presença de receptores de estrógeno e progesterona (GERALDES et al., 2000), os órgãos alvo de metástase (HAMILTON et al., 1977), a evolução clínica das neoplasias (HAMILTON et al., 1977, MOULTON, 1990) e a hereditariedade em alguns casos (MOULTON et al., 1986). Também foi demonstrado que as neoplasias mamárias de cães apresentam o fenótipo antigênico comparável àquele observado em lesões de mama em homens e mulheres (MOTTOLESE et al., 1994) e a homologia entre os genes BRCA-1 humano e do cão (SZABO et al., 1996). Existem, contudo, diferenças entre os tumores mamários do homem e do 
cão. Uma das mais importantes diz respeito à frequiência dos tumores mistos mamários que são raros nos humanos, mas são os mais freqüentes nos caninos (STRANDBERG \& GOODMAN, 1974; CASSALI, 2000).

$\mathrm{Na}$ cadela, a freqüência dos tumores mamários espontâneos é duas a três vezes superior à observada na mulher (SCHINEIDER, 1970) e a incidência de tumores malignos e benignos aumenta com a expectativa de vida e com a utilização continuada de progestágenos e se reduz com a ovariectomia em animais jovens (RUTTEMAN et al., 2001). O risco de desenvolvimento de neoplasias mamárias em cadelas castradas antes do primeiro ciclo estral é de $0,05 \%$, após o primeiro estro sobe para $8 \%$, e é de aproximadamente $26 \%$ quando a castração ocorre após o segundo estro (MORRISON, 1998). A freqüência dos tumores de mama aumenta a partir dos seis anos de idade, com rara ocorrência em cães com menos de dois anos (MOULTON, 1990). A princípio não existe predileção racial, mas alguns trabalhos apontam as raças Poodle, Dachshund, Pointer e Retrievers como predisponentes (MEUTEN, 2000; RUTTEMAN et al., 2001).

O risco de desenvolvimento do câncer de mama é essencialmente determinado pela intensidade e duração da exposição do epitélio mamário à ação conjunta da prolactina e do estrógeno (KOJIMA et al., 1996). Aparentemente a prolactina facilita a ação mitótica do estrógeno, aumentando o número de seus receptores. Mas a possibilidade da prolactina estimular a atividade mitótica das células do epitélio mamário não pode ser afastada (MULDOON, 1981). O estrógeno promove o crescimento celular por estimular a liberação do fator de crescimento tumoral alta e do fator de crescimento semelhante à insulina e por inibir o fator de crescimento tumoral $\beta$ (NORMAN \& LITWACK, 1997).

Estudos indicam que alguns fatores como a menarca precoce, menopausa tardia, obesidade, idade avançada à primeira gestação, reposição hormonal e a utilização de contraceptivos orais predispõem ao câncer de mama na mulher (HENDERSON et al., 1982; HENDERSON \& FEILGESON, 2000). Na cadela, existe muita controvérsia no que se refere aos fatores que podem estar associados aos tumores mamários. Alguns autores associam as neoplasias mamárias a desordens endócrinas decorrentes de cistos foliculares e corpo lúteo persistente, além de outros fatores como pseudogestação, nuliparidade, obesidade e utilização de progestágenos (MOL et al., 1997). Contudo, outros autores afirmam que esses fatores não são significativos para a carcinogênese mamária (MORRISON, 1998).

Mulheres obesas apresentam elevadas concentrações de estrógeno proveniente da transformação, no tecido adiposo, da androstenediona em estrona e posteriormente em estrógeno (YOO et al., 2001). Durante o primeiro trimestre da gestação o aumento progressivo das concentrações de estradiol, aumenta o risco de desenvolvimento de câncer. Com a continuidade da gestação, aumentam as concentrações da globulina transportadora dos esteróides sexuais, reduzindo a concentração plasmática de estrógeno livre, protegendo a glândula mamária das ações desse hormônio. Mas esse efeito protetor somente é observado em mulheres com gestação completa (HENDERSON et al., 1988). Em cadelas, esse efeito protetor da prenhez não é observado (RUTTEMAN et al., 2001).

A reposição hormonal aumenta o risco de câncer de mama particularmente em mulheres com história familiar dessa neoplasia (CARREÑO et al., 1999). Os contraceptivos orais aumentam a atividade mitótica das células da glândula mamária à semelhança do que ocorre no ciclo menstrual normal (VORHERR, 1987). Entretanto, o uso precoce de contraceptivos e a vida reprodutiva tardia parecem aumentar o risco, já que o tecido mamário fica mais tempo exposto ao estímulo hormonal (HENDERSON \& FEIGELSON, 2000). Em cães e gatos, a progesterona exógena estimula a síntese de hormônio do crescimento na glândula mamária com proliferação lóbulo-alveolar e conseqüente hiperplasia de elementos mioepiteliais e secretórios, induzindo a formação de nódulos benignos em animais jovens (MOL et al., 1997; RUTTEMAN et al., 2001; MEUTEN, 2002). O estrógeno estimula o crescimento ductal. Entretanto, o risco de desenvolvimento de neoplasias malignas tem sido observado na administração continua e em altas doses de estrógeno associado à progesterona (MORRISON, 1998; RUTTEMAN et al., 2001)

Receptores para estrógeno, progesterona, andrógenos, prolactina e para o fator de crescimento epidermal já foram demonstrados nos tumores de mama de cadelas, havendo também a coexistência desses receptores numa mesma neoplasia (MEUTEN, 2002). A função dos receptores hormonais nas neoplasias tem sido exaustivamente estudada. Acredita-se que exista relação entre o número desses receptores e a capacidade proliferativa das células neoplásicas (COSTA et al., 2002). Na cadela, é elevada a proporção de tumores benignos da mama positivos para receptores de estrógeno e progesterona. Ao contrário, apenas uma parte das neoplasias malignas apresentam 
esses receptores e em concentrações menores (CASSALI, 2000; GERALDES et al., 2000), pois com a progressão do tumor e aumento da malignidade ocorre redução da dependência hormonal e maior autonomia das células neoplásicas (GERALDES et al., 2000). Além disso, há correlação inversa entre o número de receptores para estrógeno com a atividade da glucose6-fosfatase e da 6-fosfogluconato-desidrogenase, enzimas conhecidas por estarem relacionadas com a malignidade das células neoplásicas (NERURKAR et al., 1990).

Em cadelas, foram observados resultados similares aos descritos na mulher, tanto pela maior expressão do MIB-1 (marcador imunoistoquímico para avaliar a proliferação celular) nos tumores malignos da mama, principalmente naqueles menos diferenciados, quanto pela correlação inversa com a imunomarcação para o receptor de progesterona (CASSALI, 2000). Verificou-se ainda relação entre o tamanho do tumor e a expressão de receptores para progesterona, sendo a imunomarcação menor nos tumores maiores que $5 \mathrm{~cm}$ (CHIARELLI et al., 2000). Contudo, trabalhos que relacionam os receptores para esteróides sexuais com o desenvolvimento de tumores mamários na cadela são escassos.

Receptores para hormônios tireoidianos também já foram observados na glândula mamária normal e neoplásica, sugerindo a participação dos hormônios da tireóide no câncer de mama da mulher (NOGUEIRA\& BRENTANI, 1996). No hipotireoidismo, o aumento da secreção de prolactina tem sido incriminado como um dos fatores que agravam o prognóstico da neoplasia mamária (SMYTH, 1997).

O leiomioma uterino é uma neoplasia da musculatura lisa presente em cerca de $20 \%$ das mulheres com 30 anos (FLISTER, 2001). Essa é também a neoplasia mesenquimal mais freqüente no útero de vacas, gatas e cadelas (MOULTON, 1990). A participação dos esteróides sexuais na gênese do leiomioma uterino firma-se pelo aparecimento do leiomioma na puberdade, pelo aumento da sua freqüência com a reposição hormonal, pelo maior crescimento dessa neoplasia durante a gestação e por sua regressão com a menopausa (MEULTEN, 2002; FLISTER, 2001). Além disso, observa-se no tecido neoplásico redução da atividade da enzima que transforma estradiol em estrona, submetendo-o à maior estímulo estrogênico. A presença de receptores para estrógeno e progesterona no leiomioma uterino reafirma a participação desses esteróides na sua gênese. Acreditava-se que a progesterona inibia o crescimento do leiomioma, mas pesquisas recentes demonstram que ela estimula o crescimento neoplásico, principalmente na fase luteínica e com o uso de progestágenos em altas doses (FLISTER, 2001).

Para HENDERSON et al. (1991), o câncer endometrial origina-se da exposição do endométrio à ação cumulativa do estrógeno. A progesterona protege as células endometriais da hiperestimulação estrogênica, pois diminui o número de receptores para o estrógeno, aumenta seu metabolismo intracelular e inibe a conversão da androstenediona em estrona, reduzindo a atividade mitótica das células endometriais (VORHERR, 1987; VOIGT et al., 1991). A obesidade é considerada fator de risco no desenvolvimento do câncer de endométrio. Mulheres obesas, antes da menopausa, produzem um nucleopeptídeo que inibe a ovulação, não havendo formação do corpo lúteo, síntese de progesterona e oposição aos efeitos do estrógeno sobre o endométrio (AKHMEDKHANOV et al., 2001). Após a menopausa, o risco de desenvolvimento do câncer de endométrio se associa à produção de estrógeno pelo tecido adiposo (HENDERSON et al., 1982). O uso de contraceptivos e a reposição hormonal à base de estrógeno elevam o risco de desenvolvimento do câncer de endométrio, ao contrário da utilização de contraceptivos combinados, constituídos por estrógeno e progesterona (VOIGT et al., 1991). A gravidez também reduz o risco, pois nesse período as concentrações de progesterona são maiores que as de estrógeno (HENDERSON et al., 1991). Nos animais domésticos, as neoplasias endometriais são raras e sua gênese ainda não foi elucidada (MEUTEN, 2002).

O câncer da superfície epitelial do ovário é frequiente em mulheres e cadelas, raro em gatas e vacas (MOULTON, 1990) e resulta de modificações hormonais complexas, aparentemente relacionadas à ovulação (FATHALLA, 1971). Após a ovulação, induzida pela ação das gonadotropinas, a superfície do ovário fica exposta à ação do estrógeno do fluido folicular, resultando em proliferação das células epiteliais da superfície do ovário (ROSKELLEY \& BISSEL, 2002). Gravidez e o uso de contraceptivos orais em mulheres reduzem o risco de desenvolvimento do câncer de ovário, pois diminuem a secreção das gonadotropinas, suprimindo a ovulação (HENDERSON et al., 1991; WHITTEMOREet al., 1992).

Os andrógenos estão envolvidos na gênese da hiperplasia e do câncer de próstata no homem, haja visto que tanto as células normais quanto neoplásicas apresentam receptores para andrógenos e que a orquiectomia inibe o crescimento tumoral (COTRAN et al., 2000). Evidências sugerem a participação do estrógeno, prolactina, testosterona e diidrotestosterona na iniciação e promoção do câncer 
de próstata (HENDERSON et al., 1982; CHAN et al., 1998). O estrógeno possui função dupla: em concentrações normais, aumenta o número de receptores para os andrógenos e em concentrações elevadas, inibe a ação da testosterona (HENDERSON et al., 1991). Já a prolactina age em sinergismo com o hormônio luteinizante, controlando a secreção de testosterona e com os andrógenos, estimulando o crescimento da próstata (HENDERSON et al., 1982). Elevadas concentrações de diidrotestosterona causam hiperplasia prostática e subseqüente transformação neoplásica em ratos (HENDERSON \& ROSS, 1996). No entanto, no homem a hiperplasia prostática não é considerada uma alteração préneoplásica (COTRAN et al., 2000). Em cães, foi comprovado recentemente, que a hiperplasia resulta da proliferação das células basais acinares mediada pela ação dos esteróides sexuais. No entanto, nos processos neoplásicos ocorre proliferação das células ductais que, na maioria, não expressam receptores para andrógenos (LEAV et al., 2001). Além disso, a castração não altera o risco de desenvolvimento das neoplasias de próstata no cão (OBRADOVICH et al., 1987).

A gestação e a infância são períodos críticos para a gênese do câncer de testículo (HENDERSON et al., 1982). O criptorquidismo decorrente da disgenesia testicular resulta da ação do estrógeno livre presente no primeiro trimestre da gravidez, período que coincide com a diferenciação das características sexuais externas do feto (WILSON, 1972). Após a puberdade, o aumento das concentrações do hormônio folículo estimulante (FSH) associado ao criptorquidismo pode aumentar a atividade do testículo normal e a partir daí predispor à transformação neoplásica (VAN VLIET et al., 1980). Nos animais domésticos, a carcinogênese no testículo parece não ser desencadeada por alterações hormonais, sendo os cães criptorquídicos mais predispostos ao desenvolvimento das neoplasias testiculares, por razões ainda desconhecidas (JONES et al., 1997).

O hormônio tireo-estimulante (TSH) é o principal regulador do crescimento e da função da tireóide. O excesso de TSH é fator predisponente para o câncer da tireóide (MEUTEN, 2002). Nos animais, domésticos é mais freqüente em cães, gatos e cavalos, principalmente em regiões onde ocorre deficiência de iodo. A presença de receptores para o estrógeno nas células neoplásicas da tireóide e a maior freqüência nas fêmeas sugere também a participação dos hormônios sexuais femininos na gênese dessa neoplasia (LUOTTO et al., 1997).
Para o osteossarcoma, postula-se que a sua incidência esteja relacionada ao aumento da atividade metabólica dos ossos (JOHNSON, 1953; MOULTON, 1990) desencadeada pela ação de vários hormônios tais como o hormônio do crescimento, os andrógenos e o estrógeno (SLOOTWEG et al., 1997). No homem, a freqüência aumenta na adolescência, período de maior metabolismo ósseo e nas idades mais avançadas, onde esse sarcoma geralmente ocorre associado à patologias ósseas benignas caracterizadas por aumento do metabolismo ósseo (HENDERSON et al., 1982). Osteossarcoma representa $80 \%$ do total de neoplasias ósseas dos cães e cerca de $70 \%$ dos gatos, mas se desconhece o papel dos hormônios na sua gênese (MOULTON, 1990).

\section{Uso de hormônios e fármacos anti-hormonais no tratamento das neoplasias hormônio-dependentes}

A utilização de hormônios e drogas antihormonais como agentes quimioterápicos tem apresentado bons resultados no tratamento de algumas neoplasias hormônio-dependentes do homem (HENDERSON et al., 1993). Nos animais, há pouca informação sobre o uso de hormônios e drogas antihormonais no tratamento das neoplasias hormôniodependentes (MORRIS et al., 1993). A remoção da glândula responsável pela secreção do hormônio indutor ou promotor da carcinogênese tem sido o procedimento mais realizado. Muitas vezes a remoção dos ovários, testículos, adrenais e hipófise conduz à regressão de alguns tumores. Exemplo disso tem sido observado nas neoplasias de mama em que há regressão dos tumores primários e das metastáses no pulmão e linfonodos após a exérese ovariana (NORMAN \& LITWACK, 1997). Entretanto, uma resposta satisfatória somente é obtida quando grande parte da neoplasia ainda é responsiva ao hormônio (HENDERSON et al.,1993).

O mecanismo de ação dos hormônios no tratamento das neoplasias hormônio-dependentes varia com a célula envolvida, mas basicamente consiste em antagonizar o hormônio que está estimulando a proliferação neoplásica (HENDERSON et al., 1991). A terapia de reposição hormonal, os contraceptivos orais, a tiroxina e o estrógeno são utilizados na prevenção e terapêutica das neoplasias de endométrio, ovário, tireóide e de próstata respectivamente.

Após a menopausa, a reposição hormonal e o uso de contraceptivos orais com baixas doses de estrógeno e altas concentrações de progesterona protegem o endométrio da ação isolada do estrógeno que, mesmo em concentrações baixas, induz hiperplasia 
(HENDERSON et al., 1993; HENDERSON \& ROSS, 1996). Os anticoncepcionais combinados e também aqueles que possuem apenas estrógeno reduzem o risco de desenvolvimento do câncer de ovário por inibirem a secreção das gonadotropinas (FATHALLA, 1971; WHITTEMORE et al., 1992; HENDERSON et al., 1993).

A administração de estrógeno ou agonistas sintéticos do GnRH bem como a orquiectomia tem sido utilizados com sucesso na fase inicial das neoplasias prostáticas (COTRAN et al., 2000). O estrógeno possui forte ação anti-androgênica e inibe a secreção de testosterona e de LH (CUI et al., 1998). O estrógeno aumenta a síntese da globulina que se liga à testosterona livre, inativando-a e inibe a enzima 5aredutase, reduzindo a conversão da testosterona em diidrotestosterona, principal andrógeno estimulador do crescimento celular na próstata (NORMAN \& LITWACK, 1997). Algumas drogas anti-androgênicas como o finasteride estão sendo utilizadas no tratamento do câncer de próstata humano. $\mathrm{O}$ finasteride inibe a enzima 5a-redutase importante para o metabolismo dos andrógenos (HENDERSON et al., 1993; CHAN et al.,1998). No entanto a terapia anti-androgênica pode induzir o aparecimento de clones celulares não responsivos à testosterona (COTRAN et al., 2000)

Pacientes com câncer de tireóide, induzido por elevadas concentrações plasmáticas de TSH, apresentam redução da massa neoplásica após a administração de tiroxina (HENDERSON et al., 1982).

O tamoxifen é um fármaco com ação antiestrogênica utilizado em mulheres na menopausa para a prevenção de recidivas e metástases do câncer de mama (KOSTOGLOU-ATHANASSIOU et al., 1998). Em cadelas, o tamoxifen tem sido utilizado para a prevenção da prenhez ou realização de aborto (MORRISON, 1998). Mas alguns testes já estão sendo realizados in vitro para avaliar a eficácia do tamoxifen, bem como in vivo, como adjuvante na exérese cirúrgica do tumor de mama (MORRIS et al., 1993). Esse fármaco suprime a proliferação das células mioepiteliais em neoplasias com receptores para o estrógeno (SHAO et al., 2000). O mecanismo de ação do tamoxifen bem como o de outros fármacos com ação anti-estrogênica não é completamente compreendido, mas acredita-se que esteja relacionado com a redução do número de receptores para o estrógeno, com o estímulo de corepressores (TGF $\beta$ ), com a inibição de co-ativadores de estrógeno (IGF e TGF $\alpha$ ) e com a inativação rápida do estrógeno (NORMAN \& LITWACK, 1997; INGVARSSON, 2001).

Embora a administração de hormônios e de fármacos com ação anti-hormonal apresentem bons resultados, sua utilização requer avaliação dos riscos e benefícios (HENDERSON et al., 1993). Mas seu uso parece causar efeitos colaterias de menor intensidade e gravidade quando comparado ao dos quimioterápicos. Em cadelas tratadas com tamoxifen, já foram relatados edema de vulva, incontinência e infecção urinária, metaplasia escamosa do endométrio, endometrite, piometra, cistos ovarianos e sinais de estro (MORRISON, 1998). Por isso um número maior de pacientes tratados se faz necessário para validar a eficácia do tamoxifen (MORRIS et al., 1993).

\section{CONCLUSÃO}

Na carcinogênese hormonal, a proliferação celular antecede ou sucede as mutações genéticas. Interessante é que os mesmos hormônios indutores ou promotores da carcinogênese também têm sido utilizados no tratamento de algumas neoplasias hormônio-dependentes. A escolha e a eficácia do tratamento podem estar diretamente relacionadas ao número de receptores hormonais presentes na neoplasia, pois a maioria desses tumores, em seu estádio de crescimento inicial, é responsiva aos hormônios antagonistas e aos fármacos antihormonais.

Assim, conhecer a expressão dos receptores hormonais nas neoplasias dos animais domésticos pode auxiliar na busca pelo tratamento. No entanto, a imunomarcação de receptores e o uso de hormônios e de fármacos com ação anti-hormonal ainda não são práticas rotineiras nos hospitais veterinários. Mas o aumento da freqüência das neoplasias e a preocupação crescente do proprietário em aumentar e melhorar a sobrevida do paciente tornam necessária a avaliação da eficácia desses procedimentos, a fim de incorporá-los na medicina veterinária, à semelhança do que já é feito na oncologia humana.

\section{REFERÊNCIAS BIBLIOGRÁFICAS}

AKHMEDKHANOV, A.; ZELENIUCH-JACQUOTTE, A,; TONIOLO, P. Role of exogenous and endogenous hormones in endometrial cancer: review of the evidence and research perspectives. Ann N Y Acad Sci, v.943, p.296-315, 2001.

BITTNER, J.J. The causes and control of mammary cancer in mice. Harvey Lect, v.42, p.221-246, 1948.

CARREÑO, M.S.R.; PEIXOTO, S.; GIGLIO, A. Reposição hormonal e cancer de mama. Rev Soc Bras Canc, n.7, p.4150, 1999.

Ciência Rural, v.34, n.2, mar-abr, 2004. 
CASSALI, G.D. Estudos morfológicos, imunohistoquímicos e citométrico de tumores mamários da cadela - aspectos comparativos com neoplasias da mama humana. 2000. 73f. Tese (Doutorado em Ciência Animal) - Patologia, Escola de Veterinária, UFMG.

CHAN, J.M.; STAMPFER, M.J.; GIOVANNUCCI, E.L. What causes prostate cancer: a brief summary of the epidemiology. Cancer Biol, v.8, p.263-273, 1998.

CHIARELLI, I. M.; CASSALI, G.D.; SCHMITT, F. O tamanho da massa tumoral pode ser indicativo de diferenciação das neoplasias da mama da cadela. In: SEMANA DE INICIAÇÃO CIENTÍFICA, 9., 2000. Anais... Belo Horizonte : UFMG/ Pró-Reitoria de pesquisa, 2000. p.95.

COOPER, G.M. Oncogenes. 2.ed. Boston : Jones and Barlett, 1995. 384p.

COSTA, S.D. et al. Factors influencing the prognostic role of oestrogen and progesterone receptor levels in breast cancer. Eur J Cancer, v.38, n.10, p1329-1334, 2002.

COTRAN, R.S.; KUMAR, V.; ROBBINS, S.L. Patologia estrutural e funcional. 6.ed. Rio de Janeiro : Guanabara Koogan, 2000. 1400p.

CUI, L et al. Slight promotion effects of intermittent administration of testosterone propionate and/or diethylstilbestrol on 3,2'- dimethyl-4- aminobiphenyl - initiated rat prostate carcinogenesis. Cancer Lett, v.122, p.195-199, 1998.

DELFINO, A.B. et al. O envolvimento de genes e proteínas na regulação da apoptose - carcinogênese. Rev Bras Cancerol, v.43, n.3, p.173-186, 1997.

DENG, C.; BRODIE, S.G. Knockout mouse models and mammary tumorigenesis. Cancer Biol, v.11, p.387-394, 2001.

FATHALLA, M.F. Incessant ovulation: a factor in ovarian neoplasia? Lancet, v.17, p.163, 1971.

FLISTER, R.A.G. Tumores benignos do útero. Informed. 2001. Acesso em: 10/08/02. On line. Disponível em: < http:/ /www.informed.hpg.ig.com.br/leiomiomas.htm>.

GERALDES, M.; GÄRTNER, F.; SCHMITT, F.N. A immunohistochemical study of hormonal receptors and cell proliferation in normal canine mammary glands and spontaneous mammary tumours. Vet Rec, v.146, p.11401148,2000 .

GUYTON, A.C. Tratado de fisiologia médica. 8.ed. Rio de Janeiro : Guanabara Koogan, 1991. 864p.

HAMILTON, J.M.; ELSE, R.W.; FORSHAW, P. Oestrogen receptors in canine mammary tumours. Vet Rec, v.101, p.258260, 1977.

HENDERSON, B.E.; FEIGELSON, H.S. Hormonal carcinogenesis. Carcinogenesis, v.21, n.3, p.427-433, 2000 .

HENDERSON, B.E.; ROSS, R.K. Prevention of hormonerelated cancers: a delicate balance. Helix, Amgen's Magaz of Biotech, v.1, p.5-11, 1996.
HENDERSON, B.E.; ROSS, R.K.; PIKE, M.C. Hormonal chemoprevention of cancer in women. Science, v.259, p.633$638,1993$.

HENDERSON, B.E.; ROSS, R.K.; PIKE, M.C. Toward the primary prevention of cancer. Science, v.252, p.1131-1138, 1991

HENDERSON, B.E.; ROSS, R.K.; BERNSTEIN, L. Estrogens as a cause of human cancer. Cancer Res, v.48, p.246-253, 1988.

HENDERSON, B.E. et al. Endogenous hormones as a major factor in human cancer. Cancer Res, v.42, p.3232-3239, 1982.

INGVARSSON, S. Breast cancer: introduction. Cancer Biol, v.11, p.323-326, 2001.

JOHNSON, L.C. A general theory of bone tumors. Bull $\mathbf{N} \mathbf{Y}$ Acad Med, v.29, p.164-171, 1953.

JONES, C.J.; HUNT, R.D.; KING, N.W. Sistema genital. In: Patologia veterinária. 6.ed. São Paulo : Manole, 1997. p.1169-1244.

KODAMA, M.; KODAMA, T. Statistical analysis of hormonal effects on the steroid responsiveness of solid Ehrlich tumors. Cancer Res, v.30, p.228-235, 1970.

KOJIMA, H. et al. Apoptosis of pregnancy-dependent mammary tumor and transplantable pregnancy-dependent mammary tumor in mice. Cancer Lett, v.110, p.113-121, 1996.

KOSTOGLOU-ATHANASSIOU, I. et al. Thyroid function in postmenopausal women with breast cancer on tamoxifen. Eur J Gynaecol Oncol, n.2, p.150-154, 1998.

LEAV, I. et al. Role of canine basal cells in postnatal prostatic development, induction of hyperplasia, and sex hormonesstimulated growth; and the ductal origem of carcinoma. Prostate, v.43, n.3, p.210-224, 2001.

LOURO, I.D. Oncogenética. Rev Soc Bras Canc, n.11, p.36-42, 2000.

LUOTTO, R. et al. Plasma-prolactin in human breast cancer. Lancet, p.433-434, 1997.

MAREEL, M.; LEROY, A. Clinical, cellular, and molecular aspects of cancer invasion. Physiol Rev, v.83, p.337-376, 2003.

McKINNELL, R.G. Cancer genetics. In: McKINNELL, et al. (Ed.). The biological basis of cancer. Cambridge : Cambridge University, 1998. p.79-114.

MEUTEN, D.J. Tumors in domestic animals. 4.ed. Iowa State : Univ. California, 2002. 788p.

MILLER, W.R. Oestrogens and breast cancer: biological considerations. Br Med Bul, v.47, p.470-483, 1991.

MOL, J.A. et al. The role of progestins, insulin-like growth factor (IGF) and IGF-binding proteins in the normal and neoplastic mammary gland of the bitch: a review. J Reprod Fertil, v.51, p.339-344, 1997. 
MORRIS, J.S.; DOBSON, J.M.; BOSTOCK, D.E. Use de tamoxifen in the control of canine mammary neoplasia. Veterinary Record, v. 133, p. 539-542, 1993.

MORRISON, W.B. Cancers in dogs and cats. Medical and surgical management. Philadelphia : Willians \& Wilkins, 1998. 785p.

MOTTOLESE, M. et al. Spontaneous canine mammary tumors. Lab Invest, v.71, n.2 p.182-187, 1994

MOULTON, J.E. (Ed.). Tumors in domestic animals. 3.ed. Berkeley : University of California, 1990. p.672.

MOULTON, J.E.; ROSENBLATT, L.S.; GOLDMAN, M. Mammary tumors in a colony of beagle dogs. Vet Pathol, v.23, p.741-749, 1986

MULDOON, T.G. Interplay between estradiol and prolactin in the regulation of steroid hormone receptor levels, nature, and functionality in normal mouse mammary tissue. Endocrinol, v.109, n.5, p.1339-1346, 1981.

NERURKAR, V.R. et al. Glucose-6-phosphate dehydrogenase and 6-phospho-gluconate dehydrogenase activities in normal canine mammary gland and in mammary tumours and their correlation with oestrogen receptors. J Comp Pathol, v.102, p.191-195, 1990

NOGUEIRA, C.R.; BRENTANI, M.M. Triiodothyronine mimics the effects of estrogen in breast cancer cell lines. J Steroid Biochem Mol Biol, v.59, n.3/4, p.271-279, 1996.

NORMAN, A.W.; LITWACK, G. Hormones. 2.ed. San Diego : Academic, 1997. 558p.

OBRADOVICH, J.; WALSHAW, R.; GOULLAUD, E. The influence of castration on the development of prostatic carcinoma in the dog. 43 cases (1978-1985). J Vet Intern Med, v.1, n.4, p.183-187, 1987

PELETEIRO M.C. Tumores mamários na cadela e na gata. Ver Port Ciência Vet, v.89, p.10-34, 1994.

PERATONI, A.O. Carcinogenesis. In: McKINNELL et al. (Ed.). The biological basis of cancer. Cambridge : Cambridge University, 1998. p.75-114.

PINES, J. Cyclins, CDKs and cancer. Cancer Biol, v.6, p.6372, 1995.

ROSKELLEY, C.D.; BISSEL, M.J. The dominance of the microenvironment in breast and ovarian cancer. Cancer Biol, v.12, p.97-104, 2002.
RUTTEMAN, G.R.; WITHROW, S.J.; MACEWEN, E.G. Tumors of the mammary gland. In: WITHROW, S.J.; MACEWEN, E.G. Small animal clinical oncology. 2.ed. Philadelphia : Sanders, 2001. p.455-477.

SCHINEIDER, R. Comparison of age, sex, and incidence rates in human and canine breast cancer. Cancer, v.26, n.2, p.419426, 1970

SHAO, Z.; RADZISZEWSKI, W.J.; BARSKY, S.H. Tamoxifen enhances myoepithelial cell supression of human breast carcinoma progression in vitro two different effector mechanisms. Cancer Lett, v.157, p.133-144, 2000 .

SLOOTWEG, M.C. et al. Estrogen enhances growth hormone receptor expression and growth hormones action in rat osteosarcoma cell and human osteoblast-like cells. J Endocrinol, v.155, p.159-164, 1997.

SMYTH, P.P.A. The thyroid and breast cancer: a significant association ? In: The Finnish Medical Society. Ann Med, v.29, p.189-191, 1997.

STRANDBERG, J.D.; GOODMAN, D.G. Breast cancer - Animal model: canine mammary neoplasia. Am J Pathol, v.75, n.1, p.225-228, 1974

SZABO, C. et al. Human, canine and murine BRCA1 genes: sequence among species. Hum Mol Genet, v.5, n.9, p.12891298, 1996

VAN VLIET, G. et al. Plasma gonadotropin values in prepubertal cryptorchid boys: similar increase of FSH secretion in uni- and bilateral cases. J Pediatr, v.39, p.253-255, 1980.

VOIGT, L. F. et al. Progestagen supplementation of exogenous oestrogens and risk of endometrial cancer. Lancet, v. 338, p.274-277, 1991

VORHERR, H. Endocrinology of breast cancer. Maturitas, v.9, p.113-122, 1987.

WHITTEMORE, A.S. et al. Characteristics relating to ovarian cancer risk. Am J Epidemiol, v.136, n.10, p.1212-1220, 1992.

WILSON, J.D. Recent studies on the mechanisms of action of testosterone. N Engl J Med, v.287, n.25, p.1284-1291, 1972.

YOO, K. et al. Postmenopausal obesity as a breast cancer risk factor according to estrogen and progesterone receptor status (Japan). Cancer Lett, v.167, p.57-63, 2001. 